Vojislav Božičković*

UDK $167 / 168$

Filozofski fakultet

DOI: $10.19090 / g f f .2018 .1 .41-51$

Univerzitet u Beogradu

\title{
RETENTION AND MEANING
}

Some philosophers have tried to account for belief retention and our belief states concerning days that we track and think of in terms of the linguistic meaning of the indexicals we use to refer to them such as 'today' and 'yesterday'. In this paper I discuss a couple of representative attempts to show that this is the case and argue that they are implausible. I end up proposing an alternative view that explains the relevant data better. In so doing, both for illustrative and argumentative purposes, I show that in this respect the case concerning days is not different from the case featuring spatio-temporal objects.

Key words: tracking, belief retention, temporal indexicals, linguistic meaning

\section{INTRODUCTION}

In a well-known passage Frege claims

(RC) If someone wants to say today what he expressed yesterday using the word 'today', he will replace this word with 'yesterday'. Although the thought is the same its verbal expression must be different in order that the change of sense which would otherwise be effected by the differing times of utterance may be cancelled out (Frege, 1918, p. 10).

The suggestion is that adjusting verbal expression is required in order for the same thought as belief-content to be expressed as the context of utterance changes. Yet, this strategy fails to provide us with some obvious standard adjustment to enable us to account for those cases in which a subject such as Rip Van Winkle has lost track of time. Suppose that on day $d$ before falling asleep Rip never forms any explicit belief other than one that he expressed by 'Today is beautiful'. After waking up, twenty years later, the belief is updated, given Rip's view of how the context has changed, in terms of 'Yesterday was beautiful'. As a

\footnotetext{
*vbozicko@f.bg.ac.rs
} 
consequence, the indexical 'yesterday' in this context designates the day before he woke up. If this is the case, we seem to be forced to adopt one of the two following mutually exclusive options:

(1) Rip mistakenly thinks that the day before he woke up was a nice day

(2) Rip thinks that the day he went to sleep was a nice day

Adopting (1) implausibly entails that Rip has forgotten (about) $d$; i.e. that he has not retained his belief that it was a nice day. Alternatively, adopting (2) makes it the case that the linguistic meaning of the indexical 'yesterday' which amounts to the previous day, does not shape Rip's way of thinking about $d$.

\section{CHARACTERS}

To be sure, according to Kaplan (1989) and Perry (1977), the linguistic meaning of indexicals such as 'yesterday' and 'today' which Kaplan calls character, designates its object, in the context of utterance, by supplying the subject with a way of thinking of the day it is about. When I express my belief about $d$ on that very day by adopting 'Today is a nice day', I think of $d$ under the character the present day, and when I want to update this belief on the following day I will adopt 'Yesterday was a nice day', and in so doing I will think of $d$ under the character the previous day. This is to say that the referent of 'today' and 'yesterday' which is in this case day $d$ is determined by the cognitive path supplied by the linguistic meanings or characters of 'today' and 'yesterday'. As a result, this position faces problems whether we adopt (1) or (2). In adopting (1), we need to abandon this link between the cognitive path and the semantic determination of reference. For, being dead to the world on the day before he woke up, which his utterance of 'yesterday' picks out, Rip does not intend to update his belief about that day nor is he cognitively fixed on or attached to that day. And, in adopting (2), we also need to abandon this link because Rip's cognitive fix and attachment to $d$ as the causal source of his relevant belief is at odds with what his utterance of the indexical 'yesterday' in this context picks out.

Kaplan and Perry agree that upon waking up Rip has retained the belief with which he began. Having noted that this reflects adversely on the 'KaplanPerry' view sketched above, Perry (1997) tries to adjust that kind of view so as to account for the Rip Van Winkle case. He suggests that Rip has retained this belief under various backup doxastic characters that are, in his view, analogous to but not derived from Kaplanian linguistic characters. The characters he suggests are 'That 
day [the day I remember] is or was beautiful' and 'That day [the day this belief was acquired] is or was beautiful'. The bracketed material identifies the underlying cognitive role involved, based on the relation that an object can have to a given episode of thought or a particular belief. It is too strong to claim, though, that the bracketed material constitutes Rip's way of thinking of $d$. For the belief Rip is having throughout does not seem to involve a detailed specification of $d$ as the day of this thought, the day I remember or the day this belief was acquired, and the like. The natural alternative is that the belief that Rip formed on $d$ is a plain indexical belief to the effect that it is beautiful that he later updates on the basis of his memory, while the bracketed material serves only as a pointer to us in theorizing about Rip. But, if so, this belief is not governed by characters as it is supposed to. ${ }^{1}$

\section{THE RETENTION OF THOUGHT}

So, how are we to account for the fact that Rip has retained the belief with which he began and acknowledge (2)? We saw that the outlined Frege-inspired strategy does not work. But, we can make use of his notion of sense as the mode of presentation of the day thought about without aligning it with linguistic meaning either in terms of Frege's own claim contained in (RC) or in terms of Kaplan's linguistic or Perry's doxastic characters.

My suggestion is this. Consider the standard case first, the case in which the subject keeps track of time. 'Today is beautiful', uttered on Tuesday, and 'Yesterday was beautiful', uttered on Wednesday', will convey the same cognitive value, i.e. involve the same mode of presentation of $d$, just in case the subject takes $d$ as the same from Tuesday through to Wednesday. This ensures that the subject thinks of $d$ under the same mode of presentation from one occasion to the next which is in turn required for the belief with which she began to be retained. In so doing, she will associate with $d$ a cluster of features and properties she takes $d$ to possess. These may include the properties of being the present day or of being the previous day. Although they respectively amount to the characters of 'today' and 'yesterday', these properties do not shape the subject's way of thinking of $d$ in the way in which they are supposed to on Kaplan's and Perry's views which were examined above. They are just properties the subject associates with $d$ alongside other properties and features. I may be unsure whether midnight has passed and refrain from accepting either 'today' or

\footnotetext{
${ }^{1}$ For a full discussion of Perry's view, see Bozickovic 2005, and for a full discussion of the Rip Van Winkle case, see Bozickovic 2015.
} 
'yesterday' in order to express the belief I have acquired about $d$ before I lost track of time. This shows that such a property need not even be involved in the mode of presentation of $d$.

Along the same lines and in acknowledging (2) and the fact that Rip's relevant belief is about $d$ suggests that his picking up 'yesterday' to express and update his belief about $d$ upon waking up shows that such a property, in this case the property of being the previous day, can mistakenly be taken to pertain to $d$. In adopting 'Yesterday was a nice day' Rip falsely believes that $d$ has the property of being the previous day. For, Rip is cognitively fixed and attached to $d$ as the causal source of his relevant belief. In adopting 'Yesterday was a nice day' Rip is surely not having a belief about the day before he woke up that it was a nice day.

True, in those cases in which everything goes smoothly and the subject keeps track of $d$ from one day to the next the linguistic meaning or character of 'yesterday' will typically play the key role in updating the subject's belief about $d$ on $d+1$. But as time goes by, in updating her belief the subject will need to resort to 'that day' in the role of a memory-based demonstrative. (Note 'that day' here does not have a fixed character.) As a result of this, her mode of presentation of $d$ needs to include various supplementary features that she associates with $d$. This is to say that all of these features together shape her mode of presentation of $d$. Typically, these will be the features by which she remembers $\boldsymbol{d}$ such as lying in the sun on the river bank and drinking a martini.

The fact that the subject will think of $d$ under the same mode of presentation as long as (inter alia) she represents $d$ as the same ensures that the identity of a mode of presentation is not affected if the features in question fluctuate as when the subject assigns new features to $d$ in the process of thinking about it over time, or withdraws those she once took it to have or else by whether these features really pertain to $d$. Similarly, a particular mode of presentation of $d$ need not involve properties that $d$ satisfies (or is believed to satisfy) uniquely. To illustrate this, consider one of Perry's examples (1980. p. 80). Smith, whose watch is an hour fast accepts 'Today is my husband's birthday'. But just before eleven, she realizes she got it wrong. It is March 1 and not March 2. She glances at her watch, at eleven, and it shows midnight - she thinks to herself 'so today is my husband's birthday'. Smith's respective assenting to and dissenting from two consecutive utterances of 'Today is my husband's birthday' shows her as thinking of $d$ under two different modes of presentation in spite of the fact that each of these modes of presentation contains as its constituent the property of being my [Smith's] husband's birthday as well as that of being the present day (though not at the same time). This would be so even if these modes of presentation 
were, respectively, to incorporate all and only the same features and properties. This way the tricky issues do not arise, such as whether every variation in the features and properties the subject takes $d$ to possess should change the identity of the mode of presentation of $d$ or whether all those features that the subject takes $d$ to possess ought to be true of $d$ in order for her to have a mode of presentation of $d$. What matters is that the fluctuation of these features does not make the object (content) of belief shifty and unstable as long as it is individuated in terms of the subject's representing $d$ as the same.

This way of individuating modes of presentation also makes them interpersonally stable. Suppose two people are having a communication about $d$ on $d+1$ both of which know which day it is but have spent $d$ in different places, being involved in different activities, such that the majority of properties that they associate with $d$ do not match. On $d+1$ the speaker utters 'Yesterday was beautiful' and the hearer who, say, spent $d$ indoors disagrees. No matter how vast the disagreement is about what properties $d$ is taken to have and no matter by which features each of them remembers $d$, both of them are thinking of $d$ under the same mode of presentation as long as both of them represent $d$ as the same day from $d$ through to $d+1$.

As a result, we avoid the undesirable consequences of the neo-Fregean view. According Evans, two people need not think of the same object that they both perceive via the same sense, i.e. under the same mode of presentation. Evans suggests that the sense via which one person thinks of an object will be different from the sense via which another person thinks about it if they identify it via two relevantly different parts. Suppose that two people who identify an object via its relevantly different parts are having a communication about it and both assent to an utterance of 'This is F'. What makes it communication, rather than misunderstanding when one of them tells the other 'This is F', is the fact that there is a single inclusive object encompassing both the part perceived by the speaker and the part perceived by the hearer (see Evans 1982, p. 333). They successfully communicate by sharing not the same, but different, suitably related senses and thoughts. What a linguistic interchange of the appropriate kind, mutual understanding - which is what successful communication achieves - requires is not shared thoughts but different thoughts which stand and are mutually known to stand in a suitable relation of correspondence (see McDowell 1984, p. 290). However, this makes senses as constituents of thoughts - as contents (objects) of belief - inter-personally shifty and unstable. It is also unclear how far we should go in slicing senses along these lines and what should be our guiding principle in so doing. We are not better off if we are to try to apply this view to the case of days. Consider again the two people who assent on $d+1$ to 'Yesterday was beautiful', knowing that they are both talking about $d$ which they 
keep tracking, and identify $d$ in terms of relevantly different properties that they associate with $d$. To claim that this makes them think about $d$ via different senses, in addition to the problems just noted, would also create an asymmetry in a position such as Evans's. Evans claims that a subject who tracks $d$ from $d$ to $d+1$ thinks of $d$ via the same sense, i.e. under the same mode of presentation. On the other hand, two people who do not think of $d$ under the same mode of presentation (via the same sense) in the sense described are said to successfully communicate by sharing not the same, but different, suitably related modes of presentation. All this is avoided if we individuate senses (modes of presentation) the way I have suggested, which is a natural way to do so. This also enables us to avoid an unnecessary proliferation of senses.

As noted, in those cases in which the subject keeps track of $d$ from one day to the next the character of 'yesterday' will typically play the key role in updating her belief about $d$ on $d+1$. The belief that $d$ is beautiful that the subject formed on $d$ on the basis of her direct encounter with $d$ and expressed by means of 'Today is beautiful' is updated on the basis of her memory of $d$ and expressed by means of 'Yesterday was beautiful'. This suggests that only certain characters can be employed to account for the change of context as one (who is unlike Rip in this respect) keeps thinking about $d$ from $d$ to $d+1$. Only certain (indexical) expressions are fit for playing the part in updating the subject's belief and not just any expressions that are about $d$ : 'today' can be replaced with 'yesterday' but not with 'October 16 ${ }^{\text {th }}, 2016$ ' even if $d$ is October $16^{\text {th }}, 2016$.

However, the subject sometimes needs to update her belief without the aid of adjusting the indexicals in this way. Suppose that on the morning of $d$, the subject thinks of $d$ that it is a nice day on the basis of her direct encounter with it. Then after spending the rest of her day by thinking about other matters she gets back to thinking about the weather and resorts to her memory to update the belief with which she began. On both these occasions, though, she will be disposed to express her belief by the same form of words - 'Today is beautiful', i.e. by means of the same indexical and the same character. This shows that there is no systematic link between characters and the types of the ways of thinking of days, i.e. types of modes of presentation.

Also of note is that when the subject thinks of $d$ on $d+1$, accepting 'Yesterday was beautiful', her mode of presentation of $d$ is going to be the same whether her belief about weather on $d$ is true or false. She might have been mistaken about the weather from the start or misremembered it later on; yet in both these cases, as well as in the case of having a true belief about it, her mode of presentation of $d$ will remain the same (provided the day is the same). It is the same mode of 
presentation of $d$ that constitutes her belief state on $d$ and $d+1$, making it (in addition to the same character used to frame it) the key common element shared by the true and the false belief.

This is to say that the subject's mode of presentation of $d$ may involve all and only the same properties whether the subject's belief about weather on $d$ is true or false. If, on the other hand, the subject changes her mind about weather on $d$ and at one point in time starts believing that she was wrong in thinking that it was beautiful, she will drop the property of being beautiful from the body of information forming her mode of presentation of $d$. If so, does this make a split in her mode of presentation of $d$ ? Not at all! The subject's mode of presentation of $d$ will remain the same as long as the subject represents it as the same day from one occasion to the next, which ensures that its identity is not affected by whether the subject is attaching new features to $d$ in the process of thinking about it over time or withdrawing those she once took it to have, or whether these features really pertain to $d$. If on $d+1$ the subject's belief about (weather on) $d$ draws upon his memory of $\mathrm{d}$, and $d$ alone, and is aimed at $d$, and $d$ alone, as its causal source, as the same day that his original belief was about, her mode of presentation of $d$ will be the same no matter which properties the subject ascribes to $d$.

Memory-based belief states of the subject are states explanatory of action and behaviour. Rip's behaviour in the foregoing scenario was the same no matter which of the suggested characters he was to accept. Similarly, the discussed case of a person being in two different memory-based belief states under two different tokens of the same character shows that it is these belief states and not the character that account for her behaviour. Acquiring such a belief state concerning $d$ requires having at some point cognitive contact with it, while accepting an appropriate character does not require this.

\section{MODES OF PRESENTATION AND LINGUISTIC STRUCTURE}

Richard (1990) holds that linguistic expressions play a key role in defining belief states. He overtly adopts the view that belief states have a linguistic structure and calls it psychological sententialism:

[It] is a view about the relation between states of belief and their content. It makes the picture of belief as a relation to a sentence an apt picture. ... Broadly speaking, it is what I take to be implicit in claims like this: In order for something to count as the belief that Reagan is a Republican, it has to have a part or an aspect that represents Reagan and a part (aspect) that represents the property of being a Republican. (Richard 1990, p. 40) 
Whether we agree with the claim that belief states have some kind of linguistic (representational) structure, or not, cases concerning belief retention such as Frege's 'today'/'yesterday' case should make it clear that the subject's mode of presentation of day $d$ captured respectively, on the two consecutive days by means of these two indexicals cannot have a structure that is modeled on the linguistic meaning of these indexicals. The fact that the subject can think of $d$ under the same mode of presentation while adopting different temporal indexicals to account for the change of context once again shows that the identity of a belief state that she is in is not tied to the identity of character. The subject may first express her belief on $d$ by means of 'Today is a nice day' and on the following day by means of 'yesterday was a nice day' while think of it under the same mode of presentation. Think also of the case in which I am unsure if midnight has passed, and refrain from accepting any indexicals (characters) while continuing to believe what I believed a couple of seconds ago before I became unsure if midnight has passed which shows that the existence of my relevant belief state is not tied to the existence of character. In spite of this, I will continue to think of $d$ under the same mode of presentation.

Similar remarks apply to demonstratively identified spatio-temporal objects. As long as I represent a spatio-temporal object from one occasion to the next as the same, I will think of it under the same mode of presentation. While, for example, I keep track of a man I am looking at, I will be in the same perception-based belief state over a period of time, although I may successively frame my belief state by means of expressions having different linguistic meanings such as 'This one is a spy', 'That person is a spy'. I may even use a descriptive sentence such as 'The man over there is a spy', 'The individual I spoke to a little while ago is a spy', and so on. My choice of expression is not governed by any rules of linguistic meaning which is to say that linguistic meaning is not constitutive of the belief state I am in. The featured descriptive sentences serve to express this dynamic thought although their linguistic meanings are not dynamic. ${ }^{2}$ Alternatively, I can choose any of these expressions to frame my belief state at a given time: at one particular point in time I may say 'This man is a spy', but to the same effect I might have said 'The man over there is a spy'. Furthermore, no particular expression needs to spring to mind in the process of being

\footnotetext{
${ }^{2}$ See Luntley 1997 who argues that dynamic perception-based thoughts are not definable by rules of linguistic meaning even when these are rules of applied linguistic meaning, but rather in terms of the subject's egocentric point of view. These rules alone, that is, do not suffice for the construction of such thoughts.
} 
in such a belief state. So, we cannot go by linguistic meaning in individuating the belief state that I am in.

There is also a reverse problem with tying cognitive significance to meaning/character consisting in the fact that the subject can be in two different cognitively significant mental states while accepting, respectively, utterances with the same linguistic meaning/character. Perry's aforementioned case concerning Smith's respective assenting to and dissenting from two consecutive utterances of 'Today is my husband's birthday' attests to this. The same happens when one disbelieves that ' That $_{1}=$ that $_{2}$ ' in the case in which two utterances of the same demonstrative are coreferential, as when one perceives one end of a ship via its bow without realizing that it is the same ship that she perceives via its stern and believes ,one of the ships” to be sailing to the Black Sea but not ,the other".

That the subject's mental states are different here follows from the fact that she has made a division in her input information which will lead her to have a rational differential doubt towards ' $\mathrm{That}_{1}$ is $\mathrm{F}$ ' and ' $\mathrm{That}_{2}$ is $\mathrm{F}$ ', where $F$ is a property which she, respectively, believes and disbelieves the given object to have. This verdict is the outcome of the Intuitive Criterion of Difference accepted by the Fregeans as well as by Kaplan and Perry in terms of their own frameworks that is in the present case applied to two different utterances of the same sentence type. It has do with the fact that modes of presentation of objects thought about need to obey a cognitive constraint stating that a rational subject cannot at the same time believe and not believe of a certain object that it has a certain property while thinking of it under the same mode of presentation. For a Fregean, in Perry's words this criterion looks like this:

If a person who understands the meaning of sentences $S$ and $S^{\prime}$ of language $L$ can consistently accept $S$ and not accept $S^{\prime}$, then $S$ and $S^{\prime}$ must express different propositions [thoughts].

Perry adopts the following version of it in conformity with his own framework:

If there is some aspect of meaning by which an utterance $u$ of $S$ and an utterance $u$ ' of $S^{\prime}$ 'differ, so that a rational person who understands both $S$ and $S^{\prime}$ might accept $u$ but not $u$, then a fully adequate semantics should say what it is (Perry 2001a, pp. 89).

\footnotetext{
${ }^{3}$ For a detailed discussion of the co-reference problem concerning identity statements concerning perceptual demonstratives, see Bozickovic 2008.
} 
But, if we adopt this criterion, it follows that the cognitive differences that arise in conformity with it cannot be captured by the linguistic meaning of indexicals or by the linguistic structure of belief states. So the former formulation of the criterion cannot be right. For, Smith's two utterances of 'Today is my husband's birthday' as well the two utterances of ' That $_{1}$ is $F$ ' and ' $\mathrm{That}_{2}$ is $\mathrm{F}$ ' differ in cognitive significance (cognitive value) in spite of having the same linguistics meaning. In the framework of the present paper, this is to say that Smith is thinking of the same day via two different senses (modes of presentation) and similarly for the case featuring the utterances of 'That ${ }_{1}$ is $\mathrm{F}$ ' and ' $\mathrm{That}_{2}$ is $\mathrm{F}$ '. This also renders the second formulation of this criterion inappropriate if we take it at its face value, i.e. if we take cognitive differences to be an aspect of meaning. In the present framework, the criterion should rather run like this:

Two modes of presentation are different if it is possible for a rational subject who entertains them to take them to present her with two different days or objects.

How this criterion is to be further constrained is not the subject-matter of this paper whose role it was to show that our relevant mental states cannot be individuated in terms of the linguistic meanings of the expressions we use to frame them, and for these purposes the stated version of this criterion will do. ${ }^{4}$

Vojislav Božičković

\section{RETENCIJA I ZNAČENJE}

Rezime

Neki filozofi pokušali su da objasne retenciju verovanja kao i naša mentalna stanja u pogledu dana koje pratimo kroz vreme, i o kojima mislimo, putem jezičkog značenja indeksičkih izraza pomoću kojih referiramo na dane, kao što su 'danas' i 'juče'. U ovom radu razmatram par reprezentativnih pokušaja da se pokaže da je to slučaj i pokazujem da su ti pokušaji bezuspešni. Kako iz ilustrativnih, tako i iz argumentativnih razloga, potom pokazujem da se u ovom pogledu slučaj koji se tiče dana ne razlikuje od slučaja koji se tiče prostorno-vremenskih objekata.

Ključne reči: praćenje, retencija verovanja, temporalni indekdikali, jezičko značenje.

\footnotetext{
${ }^{4}$ For a discussion of this criterion and a suggestion as to how it is to be applied to the perception-based demonstrative thoughts see Bozickovic 2017. In that paper, I also suggest an alternative to the neo-Fregean view such as Evans's.
} 


\section{REFERENCES}

Bozickovic, V. (2005). Do Characters Play a Cognitive Role?, Philosophical Psychology, 18 (2), 219-229.

Bozickovic, V. (2008). Cognitive Significance and Reflexive Content. Linguistics and Philosophy, 31 (5), 545-554.

Bozickovic, V. (2015). Belief Retention: A Fregean Account, Erkenntnis, 80 (3), 477-486

Bozickovic, V. (2017). Slicing Thoughts, American Philosophical Quarterly, 54 (1), 3-13.

Evans, G. (1982). The Varieties of Reference, Clarendon Press, Oxford.

Frege, G. (1918). Thoughts, in his Logical Investigations, Blackwell, Oxford, 1977, $1-30$.

Kaplan, David (1989). Demonstratives, Almog, J., Perry, J., Wettstein, H., (eds.), Themes from Kaplan, Clarendon Press, Oxford, 481-563.

Luntley, M. (1997). Dynamic Thoughts and Empty Minds, Dokic, Jerome (ed). Cognitive Dynamics, European Review of Philosophy, Vol. 2, CSLI Publications, Stanford.

McDowell, J. (1984). De Re Senses. The Philosophical Quarterly, 34 (136), pp. 283-94.

Perry, J. (1977). Frege on Demonstratives, The Philosophical Review, 86 (4), 474497

Perry, J. (1997). Rip van Winkle and Other Characters, Dokic, J. (ed.) Cognitive Dynamics, European Review of Philosophy, Vol. 2, CSLI Publications, Stanford.

Perry, J. (2001). Reference and Reflexivity, CSLI Publications, Stanford, California. Richard, M. (1990). Propositional Attitudes: An Essay on Thoughts and How We Ascribe Them, Cambridge University Press, Cambridge. 
